\title{
Information Seeking in Context: Results of Graduate Student Interviews
}

\author{
Marg Sloan \\ Research \& Instructional Services Librarian \\ The University of Western Ontario \\ sloan@uwo.ca \\ Kim McPhee \\ Research \& Instructional Services Librarian \\ The University of Western Ontario \\ kmcphee5@uwo.ca
}

\begin{abstract}
The authors conducted a qualitative research study examining the information seeking behaviours of Psychology, Sociology, and Women's Studies graduate students at a large research intensive university to determine: how graduate students find information; the roles that faculty members, fellow graduate students and librarians play in the information search; and graduate students' knowledge of information resources and services. The context of graduate student information seeking was uncovered through an analysis of the data using the trichotomy of people, place and information. Across the disciplines, M.A. students were more likely to ask for librarian assistance than Ph.D. students. The interview findings will be used to improve librarian support to M.A. students via a tailored instruction plan. The authors recommend a series of several (e.g., approximately four to eight) brief (e.g., ten-minute), strategically timed sessions offered via a first-year mandatory research methods course. The sessions introduce students to key resources, explain the role librarians can play in their research, and advertise the office hours service. This enhanced librarian support will ensure that all new graduate students have a common information seeking knowledge base and that they understand the services offered by their liaison librarians. Most importantly, it places librarians in close proximity to graduate students, providing opportunities to uncover and address their actual research needs. Future research will look at the effectiveness of this plan in supporting graduate students with their research.
\end{abstract}

\section{Keywords}

graduate students; information seeking; librarian support; instruction; qualitative interviews 


\section{Introduction}

Libraries have historically been tied to the educational endeavour. As early as 1960 the idea of incorporating library resources in the classroom "had gained momentum in public education" (Hooks and Corbett 245). Recently, the combination of increasing graduate student enrollment in Ontario (Council of Ontario Universities n.p.) and the mandate to support these students led the authors to investigate graduate student information seeking behaviours at The University of Western Ontario (Western) so that they could serve this group more effectively and efficiently. Western is located in London, Ontario, Canada and has a student population of 36,794 (Western Office of Institutional Planning \& Budgeting n.p.).

Within this broader context of increasing graduate student enrollment, individual graduate students conduct research in an evolving information environment. As Kuhlthau noted, "To neglect context is to ignore the basic motivations and impetus that drives the user in the information seeking process" (qtd in Pettigrew 802). Accordingly, the authors will paint a picture of the current graduate student research context at our institution. This context includes those people who influence graduate students' research, the role of place in conducting research, and discovering how students make use of particular information tools and services. With an understanding of how our graduate students find - or do not find - information we will be better able to offer services that support them in meaningful ways.

The authors conducted interviews to uncover the context of graduate students' research processes. While other studies have addressed the research behaviours of university students generally as well as those of graduate students specifically, our qualitative research investigated these questions in a Canadian, social science setting - with a particular focus on Psychology, Sociology and Women's Studies. Looking at information seeking in context, research will be presented that addresses the following questions.

- Who are the important people in the graduate student research environment?

- Where are graduate students doing their research?

- What information tools are graduate students using?

Uncovering this information will provide a better understanding of the context of graduate student research and how librarians can situate themselves so that they can better support graduate student research.

\section{Literature Review}

\section{People}

Graduate students rely on other people when conducting research. We are particularly interested in the differing roles that faculty, fellow graduate students and librarians play in the research process. 
Researchers at Carnegie Mellon University looked at the information seeking behaviours of graduate students across all disciplines and departments (George et al. Methodology). They found that graduate students are beginning to build a network of support, and that professors are the most influential people (Results). Students also reported that other graduate students share "websites, articles, journals, papers, movies and names of key people in the field" (George et al. Results). They found that librarian influence varied by discipline; approximately half of the humanities participants had sought help from library personnel, usually librarians. Also, librarians provided assistance with the "technical aspects of information seeking", and students were pleased with the help that they received (Results).

Like George et al., Haglund and Olsson also found that supervisors play a critical role in graduate student research, noting "colleagues and supervisors are their most important support regarding information searching" (56). Meanwhile, Kayongo and Helm found that graduate students saw librarians as less important than the resources provided by the library and will only ask for assistance as a last resort (348). Fleming-May and Yuro found that Ph.D. students do not always know how a librarian can support them. They note that "a faculty member's endorsement of a librarian's ability or helpfulness may be one of the most important factors in encouraging Ph.D. students to approach that librarian for assistance" (215).

Monroe-Gulick and Petr interviewed social science graduate students and found that they possessed proficiency in the ACRL information literacy standards but needed assistance instead with elements of the research process (331). They point out that an informal discussion group approach provides the following benefits: "establishing a rapport and relationships with the students, helping students understand the research process at the beginning of their academic careers, and creating a dynamic between student and librarian that is similar to the students' collaborative relationships with faculty" (332). They found the integration of library instruction with faculty support to be beneficial (333). Rempel also endorses relationship building and suggests targeting first year graduate students to support students at the beginning of their research process a time when they are forming relationships with individuals at the institution (543).

The role of relationships is explored in Granovetter's theory of the strength of weak ties. This theory proposes, when considering the flow of new information, that the weak ties in a person's social network are more valuable in relation to information flow than stronger ties. That is, those who have weak ties (such as graduate students and librarians) do not see each other regularly and therefore, when they do meet, the individuals are more likely to exchange new information (Pettigrew 803). Further, when information is exchanged with a weakly tied individual, this information is not acted upon until consulting with someone with a stronger tie such as a professor (803). People who are weak ties in a social network are said to "act as 'local bridges' connecting individuals situated in different social networks" (Pettigrew 803). This theory is of interest when considering librarians' influence in the graduate student setting. If librarians were to situate themselves in the classroom and/or department to share information about key resources, this shared information could potentially spread - as people consult with their 'strong ties' — to others in the department. 
In summary, graduate students are most likely to consult faculty for information related to their research, and they consult their fellow graduate students for technical information. Librarians are not often consulted; however, when they are, students are pleased with the service they receive.

\section{Place}

In addition to the librarian being peripheral to some graduate students' information seeking, some researchers have found that the library itself - both virtual and physical - is now at the periphery as well. Haglund and Olsson suggest this is due to easy access to information via the Internet (56). They also found that researchers predominantly start with Google when conducting research (55). This finding is echoed by Jamali and Asadi who found that scientists are increasingly relying on Google to find scholarly articles (286). In such an environment, graduate students are often working alone with little or no contact with a librarian. These students often do not know about key library services. It is therefore necessary to find methods to reach out to these students and educate them about library services and resources (Maughan 364).

The online environment was found to be effective for educating graduate students about library resources and services. Hoffmann et al. found that there was an interest by graduate students to learn about strategies for finding information, managing references and methods for staying current; students had a preference for online instruction over in-person instruction (Conclusions). Fleming-May and Yuro found that Ph.D. students in the social sciences are also interested in accessing library instruction from remote locations (216). We will consider various methods for providing library instruction based upon our research results.

Graduate students are looking for both social and quiet study spaces on campus (Rempel, Hussong-Christian and Mellinger 483). While students did not see the library as solving their space problem, they valued any space on campus that was separate from undergraduates and that was comfortable for long periods of study.

Antell and Engel looked at scholars' use of library space and learned that younger researchers found the library "conducive to research" (553). Younger scholars in this study were those who received their last scholarly degree in the 2000s. These younger scholars were found to more often do the following in the library: write papers, work at a table, and spend time in contemplation but, interestingly, not look for information (540). The library was a valuable place to be but not necessarily to use the resources, with one respondent noting, "the physical space of the library is very conducive to intellectual idea development" (552). Older scholars were somewhat more likely to see browsing the physical library collection as valuable. The authors conclude that libraries appear to be on track when including more study space in their libraries and less space for library materials (553). 


\section{Information Tools}

A few studies have found that students use the library for their research yet do not always know about key library resources and services (Offstein et al. 398; Maughan 364; Washington-Hoagland and Clougherty 139). In addition, George found that students prefer information that is available online, and there is a heavy reliance on the Internet - which included online library resources (Results). These authors also found that students wanted to get access to information quickly, yet they reported lacking knowledge about resources or methods for accessing these resources (Discussion). Doctoral students were more sophisticated than Master's students in terms of knowledge of resources and searching skills (Discussion).

Similarly, Barrett found that students' research is iterative: respondents noted becoming better searchers with experience (328). In addition, like Haglund and Olsson, Barrett saw the importance of understanding the needs of the students instead of focusing on what the library can offer them (330). His study underlined the importance of librarians recognizing the stages of graduate student research and targeting services to address the stage at which students are situated - Kuhlthau's critical zone of intervention (ctd at 330).

Sadler and Given coined the term affordance gap defining it as "the gap in understanding created when the users of a system do not see or do not understand the opportunities for action that the designer of the system intended" (128). They suggest that the use of library jargon or the effectiveness of linking software such as SFX as examples of affordance gaps. The biggest affordance gap uncovered in their research was the perception of information literacy sessions. Librarians in the study thought students knew about the sessions when in fact they did not, and they also assumed that the signup procedure was such that students were able to sign up whereas the study revealed this too was not the case. In their study, these authors also found that graduate students who have contact with librarians benefit from "serendipitous information gathering" such that valuable information is exchanged through informal interactions (125). They conclude that effective communication channels via personal contact with librarians is possibly the most effective tool for understanding patrons' needs and guiding their information behavior (135).

Situating librarians where graduate students can receive their assistance has been found to be beneficial to both students and librarians. Haglund and Olsson note the importance of librarians in graduate students' research environments to better understand the needs of these researchers and thereby address these students in the areas where they need assistance and not where we think they need assistance (57). These authors found that searches were done by trial and error, and the idea of contacting the library for help did not occur to graduate students yet they were receptive to assistance when it was found to be useful (55).

Fleming-May and Yuro took a broader perspective by looking at the "collective information search process" that is involved when a student is transitioning from student to scholar (214). These authors found that Ph.D. students in the social sciences do 
need guidance with research tools (e.g., databases and online catalogues) when preparing their literature reviews. Students, even at an advanced level of study, need guidance from the library, but it needs to be timed or offered in a method that is convenient for the students' schedule. They are receptive to the idea of an office hours service, but they need to be reminded about the service (214).

In summary, people are important to graduate student research, with faculty being the first people to consult followed by fellow graduate students. The librarian is approached as a last resort, and evidence suggests that the continued partnering of faculty and librarians in support of graduate student research should be fostered. Place research reveals that both the physical and virtual environments are important to graduate students. And finally, students are often turning to Google to find the information they need, not always knowing about key library resources and services. Research illustrates that, instead of focusing on what the library can do for students, librarians should incorporate themselves into their researchers' environment to learn what they need from us. Taking all of this into account, we conducted semi-structured interviews to learn how graduate students are conducting research and to uncover ways librarians can better meet graduate students' needs.

\section{Methodology}

The researchers, two social science librarians supporting Psychology, Sociology and Women's Studies, used an exploratory qualitative research approach in which semistructured interviews were conducted. This ensured that all participants were asked the same general questions while allowing the researchers to probe more deeply if participants provided only partial answers or if they discussed a point that would benefit from follow-up questions. The qualitative interview questions (see appendix) were developed based on those used by George et al. (Graduate Student Interview Script Appendix). Institutional ethics approval was sought and granted.

Participants were recruited via departmental graduate student email lists as well as posters advertising the study on key departmental bulletin boards. This self-selection process does increase the likeliness of a biased sample; however, the approach was felt to be justified in that it is an exploratory study. The total population consisted of 188 graduate students, and an interview pool of 30 to 50 participants was desired - a sample size that would reveal the information seeking processes of this user group.

Thirty-three graduate students responded to the call for participation; however, one interview was dropped due to transcription difficulties. A similar proportion of students responded from Psychology (17.1\%) and Sociology (16.9\%), while a higher percentage of the smaller Women's Studies program (33.3\%) volunteered to participate (Table 1). 
Table 1. Distribution of participants by academic department and program level

\begin{tabular}{|c|c|c|c|c|}
\hline & Total & Psychology & Sociology & Women's Studies \\
\hline M.A. & 21 & 11 & 6 & 4 \\
\hline Ph.D. & 11 & 7 & 4 & $n / a^{*}$ \\
\hline Number of participants in study & 32 & 18 & 10 & 4 \\
\hline $\begin{array}{l}\text { Number of graduate students } \\
\text { enrolled in program }\end{array}$ & 176 & 105 & 59 & 12 \\
\hline $\begin{array}{l}\% \text { of enrolled students } \\
\text { participating in study }\end{array}$ & $18.2 \%$ & $17.1 \%$ & $16.9 \%$ & $33.3 \%$ \\
\hline
\end{tabular}

*There was no Women's Studies Ph.D. program at the time of the study.

In an effort to decrease response bias, the Psychology Librarian conducted the interviews with the Sociology and Women's Studies students, and the Sociology and Women's Studies Librarian interviewed the Psychology students. Participants each received a twenty dollar campus food services voucher, noted in our calls for participation, as compensation for their time. After informed consent was given, interviews were conducted in a quiet room in the library and were taped with a digital voice recorder.

Interviews were transcribed by a research assistant then coded and analyzed using the NVivo8 qualitative software package. Much of the coding was done side-by-side such that inter-rater reliability was ensured as we coded. That is, we developed our coding together, identifying themes, and continually discussed code development as we progressed through our analysis. The data were analyzed from a qualitative perspective, and we also applied coding in order to come up with quantitative results where appropriate.

\section{Findings}

Participants demonstrated a wide range of research behaviours across academic departments and program levels (i.e., M.A. vs. Ph.D.) as well as within both of these groups. In general, the need for librarian assistance depends on how far along individual students are in their graduate careers as well as their prior research and library instruction experience. Another factor to consider is how students within a department or area of study relate to each other. Do they work at home or do they work in a lab group? These variables affect the amount of indirect support that graduate students receive from each other and that they therefore might need from a librarian. All of these factors need to be taken into consideration when planning an approach to supporting this important student group. Results of the interviews conducted with graduate students are presented within the following three categories: people, place, and information tools. 


\section{People}

The role of fellow graduate students, faculty and librarians in the graduate student experience differs greatly depending on what department students are registered in and how their work and team environments are structured.

\section{Fellow Graduate Students}

In general, fellow graduate students are the first stop for general and technical questions because they are in close proximity to one another, are not intimidating (i.e., they do not grade each other) and know the "tricks of the trade" for graduate school. These students have developed ties in their research areas or lab groups that promote more of a team environment: "We were at a conference in Chicago, 'Oh, this reminds me of so and so's study' and you pick up their little pamphlet. I feel like we're all aware of what each other's research interests are, and if we see something that we think is applicable, we pass it along" (Psychology).

Conversely, it was found that some students in large programs feel isolated from each other. "We're all kind of in our own little bubble. You do course work together, but when it comes to your research, nobody's research really alludes to each other" (Sociology).

M.A. students were more likely to seek out support from fellow students. Interestingly, only $9 \%$ of the Ph.D. students reported asking for help from their peers while $57 \%$ of the M.A. students did so. Answers to our questions around influence of people revealed some trends based on department (Figure 2).

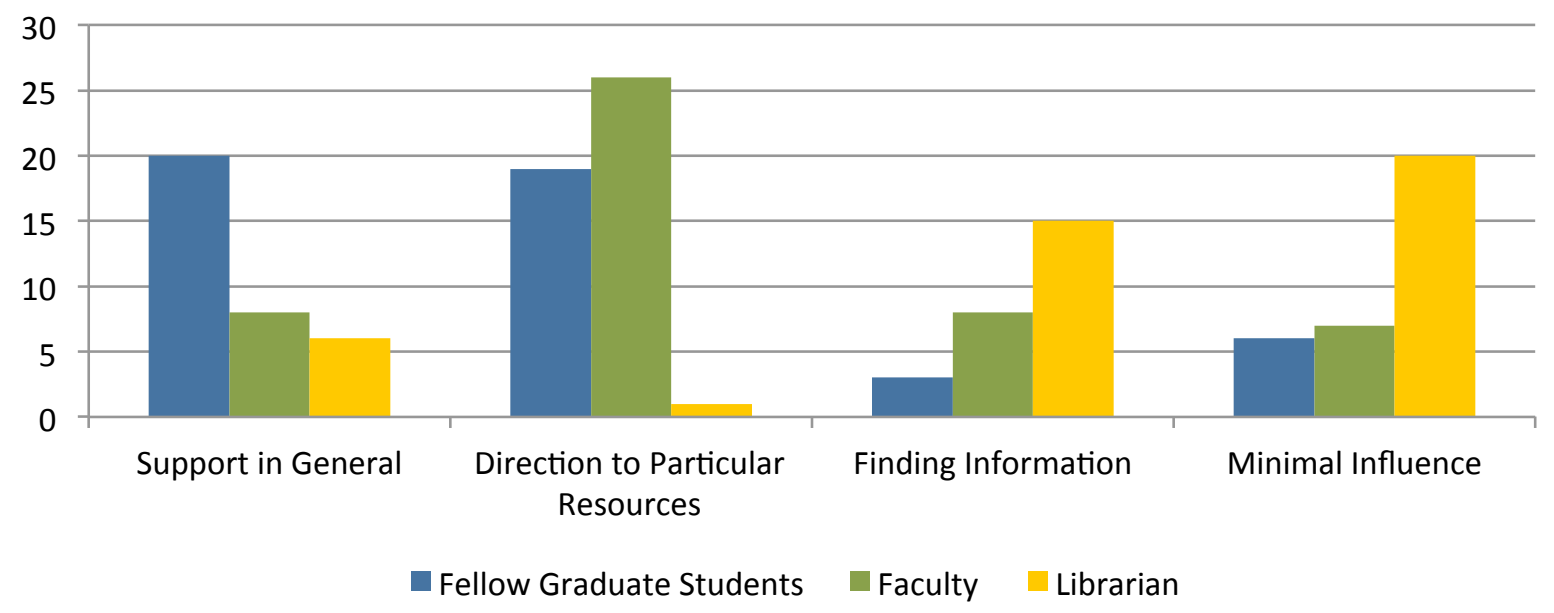

Figure 1. How do fellow graduate students, faculty and librarians assist you with finding information for your research?

Women's Studies students consistently expressed a sense of community, evidenced by their knowledge of each other's diverse research interests. Although their topics might be wide-ranging, the group shares ideas and resources quite freely. "Usually in informal 
conversations, likely someone will throw out the name of a book that they've read 'Have you read this? Oh I have it, I can get it for you'" (Women's Studies).

So, there was a wide range of responses regarding the role of fellow graduate students in finding information. Participants reported talking to their fellow graduate students about routine or technical matters, but that they generally did not seek each other out for finding research-related information. They are, however, generally aware of each other's research interests and are quite willing to pass along to each other resources that they think might be helpful.

\section{Faculty}

While graduate students approach each other with general and technical questions, graduate students reserve targeted research questions for faculty. Although it is not verbalized between faculty and graduate students, there is a clear hierarchy about who should be approached with what questions. That is, students maintain a more professional relationship with faculty as compared with the casual relationships between graduate students. "When I was starting I didn't have a research area, so he was the expert, and he gave me several papers to read to start me off. So if I'm ever confused about where I should be starting a lit search, he'll give me at least one paper that he thinks is relevant to get me started" (Psychology). Another student commented, "[I would not ask my advisor for assistance] unless it was information related to my thesis. If it wasn't related to my thesis, I'd be more likely to ask a more senior graduate student in my program" (Psychology).

\section{Librarians}

The role of librarians in graduate students' information seeking behaviour was so limited that these students often did not understand what they could ask their librarian. A theme of minimal librarian influence emerged. That is, without in-depth instruction or an established relationship, graduate students generally do not know what services librarians provide. However, those students who have received instruction and are familiar with their subject librarians are more likely to seek out one-on-one assistance. Also, graduate students sometimes avoid asking for help because their search results are "good enough", even though they sense that there might be better resources available. "I haven't actually used [librarian services] before, but there have been times where I just know there's information out there, I don't know how to figure out the keywords to get at it, so I could see a librarian being very helpful in that situation" (Sociology). Some recognize the expertise of librarians, "I guess because it's your job to know how all the information is gathered and stored and organized, some of the more refined details of literature searching, we don't know because all of the grad students do this by trial and error most of the time" (Psychology).

This is a busy group of people and they do not have time to ask for help. "We're all busy people, and we're running around trying to do ten things in a day and that's usually one of the things [talking to the librarian], it's the eleventh on the list that never quite happens, and the next day it ends up at number eleven once again. So, I know it's bad, 
but at some point I intend to take advantage of that, I've got a few years left" (Psychology). Finally, their work styles affect their likeliness of asking for help. They tend to work late into the evening when librarian assistance is not instantly available at our institution.

Interestingly, graduate students tend to approach librarians with questions that they do not believe their fellow graduate students would be able to answer or that would be a "bother" to their advisors. "I see [my librarian] as very approachable. She gave a really good beginning of the year presentation for the incoming Master's students, and I feel like if I needed some help, I feel like I could go to [her] office hours and she would be able to help me out" (Psychology).

\section{Place}

We found that the library and people have moved to the periphery of information seeking. Librarians' engagement with researchers does not happen easily in such an environment as opportunities for in-person interactions are disappearing. One student noted: "I guess the Internet kind of makes it easy to just go it alone. And I think a lot of people get into that mode where you can just go on the Internet at any time of day - in the middle of the night — and do your research" (Women's Studies).

At the same time, we found a preference for online support, as reflected in the following comment, "I know one of the things that [noted institution] had through their career website, was online tutorials, and I find that those are very helpful as well sometimes too as a general primer" (Psychology).

Our research revealed that students are conducting research in their homes, in their department offices and anywhere they can connect to the Internet. At the same time they also value opportunities to connect with fellow students and would welcome group space in the library. "I feel like a mid-size room [would be best] with the potential to have a couple of people in case people wanted to come in and do collaborative work" (Women's Studies).

Students also noted the importance of having quiet places to work, "when I need to do work, I need total silence which is why I often work at home, because there's too many distractions everywhere" (Women's Studies).

When asked how the library could provide better space for graduate students many noted the need for dedicated space for graduate students. "I tried to use the library early on in September when I moved here, but it's very undergrad oriented, much noisier than I would want as a grad student" (Psychology).

Both of the authors provide office hours in their respective academic departments. At the time of the interviews, the service had been offered for only three months. While the majority of the participants thought that office hours could be beneficial, very few had actually attended the office hours service. It seems likely that participants accurately reported whether they had attended office hours; however, there could have been a reporting bias when they stated that they thought office hours could be beneficial. "I 
think it would be [useful]. I'm not exactly sure what services she might offer, but it would be a good resource" (Psychology).

\section{Information Tools}

When asked to describe how they go about finding appropriate "resources or materials or information" for their research, most Ph.D. students (82\%) reported starting from a known database (e.g., PsycINFO or SocINDEX) slightly more often than M.A. students (71\%), whereas M.A. (43\%) students are more likely to begin with the library catalogue than are the Ph.D. students (27\%). The divide across the disciplines is more telling, with $60 \%$ of Sociology students reporting starting from a known database and the same number reporting using the catalogue, whereas 50\% of Women's Studies students start with a known database and fully $100 \%$ of these students reported using the library catalogue (Figure 2). Conversely, $89 \%$ of Psychology students start with a known database and only $11 \%$ of this group report using the catalogue. "PsyclNFO is pretty much our first port of call" (Psychology).

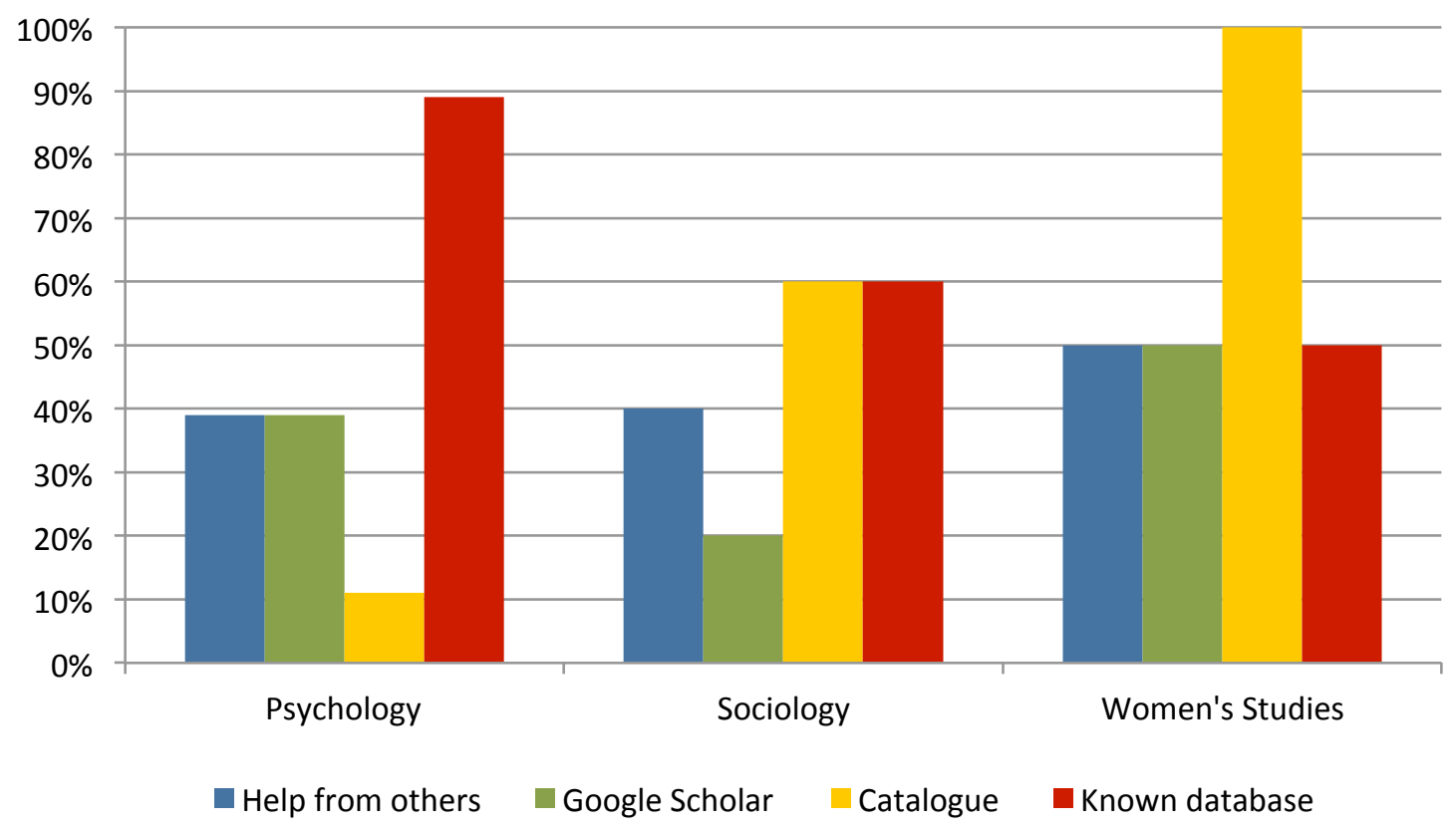

Figure 2. Describe how you go about finding resources or materials or information for your research.

Regardless of their search technique, participants often reported feeling frustrated with the search process as evidenced in the following comment, "My researching is very sporadic and I'm lucky if I come across what I need and then it's a good day, but if I don't come across what I need then I get really frustrated" (Sociology).

Google Scholar and citation chaining play an important role in students' information seeking. One third reported using Google Scholar, with one student noting, "Google 
Scholar plays a fairly significant role. It's probably $50 \%$ of the time I've used Google Scholar, and then $50 \%$ of the time l've used the BIOSIS database" (Psychology).

Other students note that they use Google Scholar when frustrated or when searching for interdisciplinary topics: "I sometimes use the search engines like Soc Abstracts, or SocINDEX. But I sometimes find that I don't get very many relevant resources, and I try switching my search words and I change the date and I rank by relevance and sometimes stuff comes up, sometimes it doesn't and if it doesn't I go to Google Scholar" (Sociology). Another student commented, "Mostly I actually use Google Scholar. I find it's helpful because I'm bridging two areas, and it's a pain to go and use PsycINFO and then say 'what's a good medical one?' And I'm not really sure. [I could] try PubMed or something" (Psychology).

Approximately half of each group, across level and discipline, reported using citation chaining to find resources. That is, they reviewed the reference lists of helpful papers and then sought out some of the cited papers. The students also reported forward citation searching when following the impact of a particular author's work. The widest range of this behaviour was between Psychology students (61\%) and Sociology students (40\%). "I try and find a key paper in that area, a meta-analysis or a review paper, and then I always look at the bibliography or reference section to guide me on where to go next" (Psychology).

\section{Discussion}

The authors looked at the context of graduate students' information seeking. Similar to the findings of Fisher, Durance and Hinton that membership size influences "the way information is created and exchanged" (2007 para.1), it was found that the physical and social structure of academic departments and the campus itself affects who influences graduate students' information seeking behaviour. Fellow graduate students are often the first stop for routine questions and general guidance but not for research-related information. This is the place for faculty or advisors whom graduate students approach with their targeted research questions; this important role is also noted by Kayongo and Helm (348). Some barriers to graduate students approaching librarians for help include: not knowing what they can ask, working late hours, and their desire for instant help. Addressing these affordance gaps, as defined by Sadler and Given, will be critical to librarians' success in partnering with graduate students and supporting their research needs (135).

Our findings that Ph.D. students are less likely to ask for help supports Barrett's and George's findings that the research process is iterative. That is, the Ph.D. students have conducted more research and therefore have developed their information seeking skills. This is reflected in their lower likelihood to ask for assistance from fellow graduate students, faculty or librarians. As well, Ph.D. students are further along in the research process; that is, more of their time is spent on data collection and analysis. Conversely, M.A. students are newer to the research process, and we saw these students seeking guidance from advisors on developing their research topics. Because this group is 
actively engaged in literature searching, this is a critical zone of intervention where librarians can provide support.

Research has been presented that demonstrates that librarians are a weak tie in a graduate student's social network. When introducing new search strategies or research tools to graduate students, if we apply Granovetter's theory of weak ties, we may also benefit the student's advisor or other graduate students as the information would be discussed with these people before being utilized. In this way, as Pettigrew discussed, librarians can act as bridges or connectors to other individuals in graduate students' social network (803). Holding office hours and assisting students individually or providing instruction in M.A. level classes could enhance information flow regarding research resources and services within the department. Such activities could have a ripple effect increasing the true support received from librarians.

The places students are conducting research are many, and both quiet study space and collaborative learning spaces are valued. The library and librarian have moved to the periphery as graduate students increasingly are conducting their research via the Internet and choosing not to enter the library or consult the librarian. When they do visit the library, they find it more suited to the undergraduate population. Haglund and Olsson's research also found that the environment of the library has changed to being a "living room" for undergraduate students. In such an environment researchers "feel outnumbered, and sometimes unwelcome" (56).

When considering the place of instruction, we found that students valued in-person instruction but also noted the value of online tutorials. Librarians can increase their visibility to graduate students through a physical presence in departments and virtual presence through online tutorials and chat services. The authors situated office hours services in the academic departments with the goal of meeting the students in a place where they are working. Similar to Monroe-Gulick et. al.'s informal group discussions, our office hours service provides opportunities for students to ask for librarian assistance in areas where they are experiencing difficulty and relationship building is supported. These same students may consider librarian assistance the next time they encounter a research challenge.

The majority of students reported using known academic databases or the library catalogue, whichever is most appropriate to their discipline. Google Scholar is a popular resource for some of our students, similar to George et al.'s findings of the Internet being used by half of their participants (Internet Resources para 2). This information indicates that we should continue in our instruction efforts around the use of the catalogue and academic databases and also provide instruction on effective methods for searching Google Scholar.

Taking all of the findings into account, an instruction plan has been developed aimed at those graduate students whom Rempel suggests are most in need of librarian assistance: first year M.A. students (2010 543). We recommend a series of several (e.g., approximately four to eight) strategically timed brief (e.g., ten-minute) sessions offered via the first year mandatory research methods course in the graduate students' 
respective departments. These brief sessions would introduce students to key resources, explain the role librarians can play in their research and advertise the office hours service. These sessions are in addition to a longer in-class library session already incorporated into the course. This enhanced librarian support would ensure that all new graduate students have a common information seeking knowledge base, and that they understand the services offered by their liaison librarians. Most importantly, it would place librarians in close proximity to graduate students providing opportunities to uncover and address their actual research needs.

\section{Conclusion}

The context of graduate student information seeking is one in which they are often accessing ebooks, journals and free Internet resources independently. They rely on their fellow graduate students for day-to-day information, on faculty for targeted research guidance, and librarians have a varied influence on students' research — often depending on prior liaison activities. In such an environment we recognize the important placement of librarians in graduate student research to learn what their research needs are and how best librarians can support them.

Future research opportunities include assessing librarians' success in understanding the context of graduate student information seeking and our success in supporting these students given this new understanding. Our findings will inform our practice, and it would be interesting to study graduate student's information seeking at other academic institutions. Librarians will continue to strive to understand and meet graduate students' research needs as these researchers endeavour to navigate the ever-evolving information environment.

\section{Acknowledgements}

The authors would like to thank Carole George, Kristin Hoffmann, Dr. Pam McKenzie, Dr. Ken Meadows, Melanie Mills, Dr. James O'Brien, and Dr. Anabel Quan-Haase for their helpful suggestions. This research would not have been possible without the Research on Teaching Small Grants Program hosted by the Teaching Support Centre, The University of Western Ontario and the Social Sciences and Humanities Research Council of Canada Internal Travel Grant Award offered by Research Development \& Services, The University of Western Ontario.

\section{Works Cited}

Antell, Karen and Debra Engel. "Conduciveness to Scholarship: The Essence of Academic Library as Place.” College \& Research Libraries. 67.6 (2006): 536-560. Print.

Badke, William. "Can't Get No Respect: Helpful Faculty to Understand The Educational Power of Information Literacy." Reference Librarian. 43. 89/90 (2005): 63-80. Print. 
Barrett, Andy. "The Information-Seeking Habits of Graduate Student Researchers in the Humanities." Journal Of Academic Librarianship. 31.4 (2005): 324-331. Print.

Council Of Ontario Universities. Applications \& Enrolment - Council Of Ontario Universities. 2010. Web. 24 June 2011.

<http://www.cou.on.ca/statistics/applications---enrolment.aspx>.

Department of Communications and Public Affairs. Prospective Students. January 16, 2008. Web. 16 July 2010. <http://communications.uwo.ca/prospective_students/international.html>

Fisher, Karen E., Joan C. Durrance, and Marian B. Hinton. "Information Grounds and the Use of Need-Based Services by Immigrants in Queens, New York: A Context-Based, Outcome Evaluation Approach." Journal of the American Society for Information Science \& Technology. 55.8 (2004): 754-766. Print.

Fisher, Karen E., Carol F. Landry, and Charles Naumer. "Social Spaces, Casual Interactions, Meaningful Exchanges: 'Information Ground' Characteristics Based on the College Student Experience." Information Research - An International Electronic Journal. 12.2 (2007). Web. 1 June, 2012. <http://informationr.net/ir/122/paper291.html>.

Fleming-May, Rachel and Lisa Yuro. "From Student to Scholar: The Academic Library and Social Sciences Ph.D. Students' Transformation." portal: Libraries and the Academy. 9.2 (2009): 199-221. Print.

George, Carol, Alice Bright, Terry Hurlbert, Erika C. Linke, Gloriana St. Clair, and Joan Stein. "Scholarly Use of Information: Graduate Students' Information Seeking Behaviour." Information Research - An International Electronic Journal. 11.4 (2006). Web. 1 June, 2012. <http://informationr.net/ir/11-4/paper272.html>.

Haglund, Lotta and Per Olsson. "The Impact on University Libraries of Changes in Information Behavior Among Academic Researchers: A Multiple Case Study." The Journal of Academic Librarianship. 34.1 (2008): 52-59. Print.

Hooks, James D. and Corbett, Frank Jr., "Information literacy for off-campus graduate cohorts”, Library Review 54 (January 2005): 245-256. Print.

Hoffmann, Kristin, Fred Antwi-Nsiah, Vivian Feng, and Meagan Stanley. "Library Research Skills: A Needs Assessment for Graduate Student Workshops." Issues in Science and Technology Librarianship. 53 (2008). Web. 1 June, 2012. <http://www.istl.org/08-winter/refereed1.html>.

Jamali, Hamid R. and Saeid Asadi. "Google and the Scholar: The Role of Google in Scientists' Information Seeking Behaviour." Online Information Review. 34.2 (2010): 282-294. Print. 
Kayongo, Jessica and Clarence Helm. "Graduate Students and the Library: A Survey of Research Practices and Library Use at the University Of Notre Dame." Reference and User Services Quarterly. 49.4 (2010): 341-349. Print.

Maughan, Patricia. "Library Resources and Services: A Cross-Disciplinary Survey of Faculty and Graduate Student Use and Satisfaction." The Journal of Academic Librarianship. 25.5 (1999): 354-366. Print.

Monroe-Gulick, Amalia and Julie Petr. "Incoming Graduate Students in the Social Sciences: How Much Do They Really Know About Library Research?” portal: Libraries and the Academy 12.3 (2012): 315-335. Print.

Offstein, Evan H., Miriam B. Larson, Andrea L. Mcneill and Hasten M. Mwale. "Are We Doing Enough for Today's Graduate Student?" The International Journal of Educational Management. 18.7 (2004): 396-407. Print.

Pettigrew, Karen E. "Waiting for Chiropody: Contextual Results from an Ethnographic Study of the Information Behaviour Among Attendees at Community Clinics." Information Processing and Management. 35.6 (1999): 801-817. Print.

Rempel, Hannah G. "A Longitudinal Assessment of Graduate Student Research Behavior and the Impact of Attending a Library Literature Review Workshop." College \& Research Libraries 71.6 (2010): 532-548. Print.

Rempel, Hannah G., Uta Hussong-Christian, and Margaret Mellinger. "Graduate Student Space and Service Needs: A Recommendation for a Cross-Campus Solution." The Journal of Academic Librarianship. 37.6 (2011): 480-7. Print.

Sadler, Elizabeth B. and Lisa M. Given. "Affordance Theory: A Framework for Graduate Students' Information Behavior." Journal of Documentation. 63.1 (2007): 115141. Print.

Washington-Hoagland, Carlette, Leo Clougherty, Dorothy Persson, Hope I. Barton, Jim Cheng, John Forys and Christine Walters. "Identifying the Resource and Service Needs of Graduate and Professional Students - The University of lowa User Needs of Graduate Professional Series." portal: Libraries and the Academy. 2.1 (2002):125-143. Print.

University of Western Ontario Office of Institutional Planning and Budgeting. Five Year Enrolment Comparison. 2012 Web. 16 July 2010.

<http://www.ipb.uwo.ca/documents/2012_five_year_enrolment_comparison.pdf> 


\section{Appendix}

\section{Semi-Structured Interview Questions}

1. a) Tell me about your research interests.

b) What research have you completed or plan to complete?

2. Can you tell me how you arrived at your research question?

OR: If you do not yet have a research question, how do you plan on developing this question?

3. What kind of resources or materials or information have you used or do you plan to use in your research?

4. Are you interested in using electronic books for your research? Why?

5.a) Describe how you go about finding (appropriate?) resources or materials or information for your research?

IF NEEDED: Tell me more.

OR: If not finding needed resources: Where have you looked?

OR: If starting at Google (or other search engine): What is your process when you get to Google (or other search engine)?

6. How do you stay current with the literature in your area?

7. a) What role do non-library websites play in finding your research information?

b) How do you arrive at these resources?

c) How satisfied are you with what you find?

IF NEEDED: Tell me more about this.

8. Do you read blogs?

If yes, would you be interested in a (sociology, women's studies, psychology) research blog?

9. What are the criteria you would use to assess the quality of the resources or materials or information you have obtained?

IF NEEDED: That is, how do you judge whether you should use a particular "bit" of information?

10. How do your professors or advisors assist you with finding information for your research?

11. How do your fellow graduate students assist you with finding information for your research? 
12.a) How do you see librarians assisting you with your research?

b) Are librarian office hours in your department beneficial to you?

13. Do you use the Western Libraries' online resources? If NO - Why not?

If YES a) How OR In what way OR What for?

b) How convenient is that?

14. How reliant are you on interlibrary loan to obtain needed research materials? (If not reliant on ILL) How do you obtain materials not owned by Western Libraries?

15. a) How do you go about managing or storing the information that you have obtained?

b) Do you need help or training with this?

c) If yes, what should this help look like?

16. Have you ever received any training in finding information for your research?

17. How could your information seeking be improved?

18. How could the library provide better physical space for graduate students? IF NEEDED: Are you interested in group study space?

IF NEEDED: Are you interested in individual study carrels?

19. Is there anything you would like to add?

\section{Demographic Questions}

1. What department are you in? (Sociology, Women's Studies, Psychology)

2. Are you currently working toward your Master's or Ph.D.? What year are you in?

3. Are you studying full-time or part-time?

4. Are you an international student? $y / n$

5. At what institution did you complete your undergraduate work?

6. Is your current research for your course work or thesis?

7. What is your age?

8. What is your gender? 